\title{
Blood-derived angioblasts accelerate blood-flow restoration in diabetic mice
}

\author{
Gina C. Schatteman, ${ }^{1}$ Heather D. Hanlon, ${ }^{1}$ Chunhua Jiao, ${ }^{1}$ \\ Sherry G. Dodds, ${ }^{2}$ and Barbara A. Christy ${ }^{2}$ \\ ${ }^{1}$ Anatomy and Cell Biology, University of Iowa, Iowa City, Iowa, USA \\ ${ }^{2}$ Molecular Medicine, University of Texas Health Science Center, San Antonio, Texas, USA \\ Address correspondence to: Gina C. Schatteman, Anatomy and Cell Biology BSB 1-402, University of Iowa, Iowa City, \\ Iowa 52245, USA. Phone: (319) 335-7765; Fax: (319) 335-7198; E-mail: Gina-Schatteman@uiowa.edu.
}

Received for publication December 7, 1999, and accepted in revised form July 5, 2000.

\begin{abstract}
Endothelial cell progenitors, angioblasts, have been detected in the peripheral blood of adult humans, mice, and rabbits. These cells have been shown to incorporate into the endothelium of newly forming blood vessels in pathological and nonpathological conditions. Here we investigated the possibility that the CD34-expressing leukocytes (CD34+ cells) that appear to be enriched for angioblasts could be used to accelerate the rate of blood-flow restoration in nondiabetic and diabetic mice undergoing neovascularization due to hindlimb ischemia. $\mathrm{CD} 34^{+}$cells did not accelerate the restoration of flow in nondiabetic mice, but dramatically increased it in diabetic mice. Furthermore, $\mathrm{CD}^{2} 4^{+}$cells derived from type 1 diabetics produced fewer differentiated endothelial cells in culture than did their type 2 diabetic-or nondiabetic-derived counterparts. In vitro experiments suggest that hyperglycemia per se does not alter the ability of angioblasts to differentiate or of angioblast-derived endothelial cells to proliferate. In contrast, hyperinsulinemia may enhance angioblast differentiation but impair angioblast-derived endothelial cell survival or proliferation. Our findings suggest that $\mathrm{CD} 34^{+}$cells may be a useful tool for therapeutic angiogenesis in diabetics.
\end{abstract}

J. Clin. Invest. 106:571-578 (2000).

\section{Introduction}

Reports of circulating and blood- or bone marrow-derived endothelial cells (ECs) have appeared in the literature since at least the 1930s (1-5), and reports of endothelialization of grafts by blood-derived cells have been appearing almost as long as synthetic arterial grafts have been in use (6-10). All of these studies pointed to the presence of ECs or their progenitors in the blood, but their identity remained elusive. In 1997, we demonstrated that specific subsets of leukocytes appear to be enriched for EC progenitors (angioblasts) (11). These include human CD34-expressing cells (CD34+ cells), human and rabbit flk-1-expressing cells (flk-1+ cells), and mouse Sca-1-expressing cells (Sca- $1^{+}$cells). Cells from these enriched leukocyte fractions differentiated in vitro and in vivo into ECs $(11,12)$. In our earlier study the $\mathrm{CD} 34^{+}$-derived ECs were spindle shaped in vitro. These spindle-shaped cells formed tubelike structures, took up acetylated LDL (acLDL), and expressed Tie-2, and only the spindle-shaped cells in these cultures had all three of these properties (11).

The antigens used to enrich angioblasts are expressed by a relatively small fraction of leukocytes. Interestingly, human $\mathrm{CD} 34^{+}$blood cells are highly enriched for hematopoietic stem cells, and further enrichment is achieved when cells are coselected for CD34 and flk-1 expression $(13,14)$. Similarly, the Sca- $1^{+}$murine leukocytes are enriched for hematopoietic stem cells $(15,16)$. Hence, angioblasts may be related to hematopoietic stem cells, an appealing idea since endothelial cells and hematopoietic cells appear to be derived from the same embryological precursor $(17,18)$.

Several studies suggest that both endogenous and exogenous blood-derived cells can participate in angiogenesis in vivo. Human $\mathrm{CD} 34^{+}$cells injected into nude mice and rats undergoing neovascularization due to hindlimb ischemia incorporate into the neovasculature and express EC antigens (11). Similarly, when endogenous $\mathrm{CD} 34^{+}$cells are removed from a rabbit, labeled with octadecyl indocarbocyanine (DiI, a fluorescent dye), and reinjected into the rabbit after induction of hindlimb ischemia, DiI-labeled cells incorporate into the neovasculature (11). Recently, studies have used hematopoietic chimeras to study the role of blood-derived cells in vascularization in pathological and nonpathological states. Mice were sublethally irradiated to destroy the regenerative capacity of the hematopoietic system. The hematopoietic system was then reconstituted using hematopoietic cells from syngenic transgenic mice. The presence of the transgene allowed blood-derived cells to be distinguished from all other body cells. Using this model, blood-derived cells were shown to incorporate into neovasculature associated with wound-healing, tumorigenesis, myocardial ischemia, and corpus luteum formation (19).

Beyond the phenomenology of their ability to incorporate into neovasculature and endothelialize grafts, little is known about the biology of blood-derived angioblasts. Little is known about the extent to which 
they normally incorporate into existing vasculature or neovasculature or about how disease may influence their biology. Recent work suggests that ischemia either increases the number of angioblasts and/or enhances their ability to differentiate (12). However, these studies have not addressed the possibility that exogenous angioblasts might be used to augment vascularization or restore blood flow to ischemic tissue.

Diabetics commonly suffer cardiovascular complications, including peripheral vascular disease (20-21). Collateralization is insufficient to overcome the loss of blood flow through occluded arteries in patients with peripheral vascular disease, and the problem is exacerbated in diabetics in whom collateralization is depressed (22-23). This leads to severe pain due to limb ischemia and often loss of a limb. The mechanisms that hinder rapid revascularization in diabetic patients remain poorly understood, but angioblast misregulation, death, or dysfunction may contribute to the severe course of cardiovascular complications seen. Accordingly, exogenous angioblasts might be used to augment compromised vascularization in diabetics.

We tested the ability of angioblast-containing CD34 ${ }^{+}$ cells to accelerate the restoration of blood flow to the limb in a mouse model of hindlimb ischemia in nondiabetic and diabetic mice. The in vitro characteristics of diabetic- and nondiabetic-derived angioblasts were also compared, and the effects of glucose and insulin on cultured angioblasts were examined. Our data demonstrate that injection of exogenous CD34 ${ }^{+}$cells can accelerate the rate of restoration of flow to ischemic limbs of diabetic mice. Furthermore, our in vitro findings suggest that angioblast function is compromised in type 1 diabetics and that these effects are not mediated directly through hyperglycemia. Additional evidence suggests that insulin may play an important role in angioblast or angioblast-derived endothelial cell function.

\section{Methods}

Isolation and labeling of CD $34^{+}$cells. Human blood was collected from 21 nondiabetic and 16 type 1 - and 17 type 2-diabetic volunteer donors, according to protocols approved by the University of Iowa Institutional Review Board. For studies involving only nondiabetic cells, $60-85 \mathrm{~mL}$ of blood was collected into $10 \mathrm{~mL} 0.13$ $\mathrm{M}$ sodium citrate as anticoagulant and used immediately. For studies involving diabetic cells, 8-9 mL of diabetic or nondiabetic blood was collected into vacutainers containing $50 \mathrm{mM}$ EDTA and used within 3 hours. Blood was diluted with 0.5 volumes PBS/AC (1.1 mM $\mathrm{KH}_{2} \mathrm{PO}_{4}, 3 \mathrm{mM} \mathrm{Na}_{2} \mathrm{HPO}_{4}, 0.9 \% \mathrm{NaCl}, 0.13 \mathrm{M}$ sodium citrate, $\mathrm{pH}$ 7.2), and the leukocytes were fractionated from red blood cells by centrifugation on Histopaque 1077 (Sigma Chemical Co., St. Louis, Missouri, USA) gradients according to the manufacturer's instructions. Leukocytes were washed once in PBS/AC and twice in PBS/AC with 2\% BSA (PBS/AC/BSA), then resuspended in $\mathrm{PBS} / \mathrm{AC} / \mathrm{BSA}$, and two aliquots were counted using a hemacytometer to determine input cell number. $\mathrm{CD}_{3} 4^{+}$cells were isolated from the leukocytes using the CD34 Cell Selection System (Dynal, Lake Success, New York, USA) according to the manufacturer's instructions, and two aliquots of the freshly isolated $\mathrm{CD} 34^{+}$cells were counted using a hemacytometer to determine cell number. Leukocytes depleted of CD34+ cells (CD34- cells) were kept as controls. Since $\mathrm{CD}^{+} 4^{+}$cells represent less than $0.5 \%$ of leukocytes before $\mathrm{CD}_{34}{ }^{+}$depletion, the $\mathrm{CD} 34^{-}$cell population is essentially pure $(24,25)$.

For CM-DiI (Molecular Probes, Eugene, Oregon, USA) labeling, freshly isolated $\mathrm{CD}^{-} 4^{+}$or $\mathrm{CD} 34^{-}$cells were resuspended at $10^{6}$ cells $/ \mathrm{mL}$ and incubated in 2 $\mu \mathrm{g} / \mathrm{mL}$ CM-DiI in media for 5 minutes at $37^{\circ} \mathrm{C}$, then 15 minutes on ice. Cells were pelleted and washed three times in medium $\left(10^{6}\right.$ cells $\left./ \mathrm{mL}\right)$ to remove unincorporated dye. In the in vitro experiments, CM-DiI labeling at this concentration had no effect on cell viability.

Cell culture and uptake of AcLDL. Except as noted, bloodderived cells were plated at $1-4 \times 10^{5}$ cells per well in 24well trays precoated with $5 \mu \mathrm{g} / \mathrm{cm}^{2}$ fibronectin, according to the manufacturer's instructions. Cells were cultured in $5 \% \mathrm{CO}_{2}$ at $37^{\circ} \mathrm{C}$ in M199 (12340; Life Technologies Inc., Gaithersburg, Maryland, USA), 20\% heatinactivated fetal bovine serum, $2 \mathrm{~mL} / \mathrm{L}$ bovine brain extract (CC-4092; Clonetics, San Diego, California, USA), and $2 \times$ antibiotic/antimycotic (15240-0620; Life Technologies Inc.). The medium was changed on the third day after plating and every 3 days subsequently. To test the effects of insulin, cells were plated as above, except bovine insulin (27 U/mg; Sigma Chemical Co.) was added to a final concentration of $3,6,12$, or 18 $\mu \mathrm{g} / \mathrm{mL}$. To test glucose's effect on angioblasts, L-glucose or D-glucose (Sigma Chemical Co.) was added to a final concentration of $30 \mathrm{mM}(540 \mathrm{mg} / \mathrm{dL})$. Glucose and insulin were added at all medium changes. In all experiments for all conditions, wells were prepared in duplicate or triplicate and cell numbers determined by counting 11 representative fields per well ( $5 \%$ of well) using phasecontrast microscopy. Experiments were performed four to six times for each time point and analyzed using a Student's paired $t$ test. CD $34^{+}$cells from a single vacutainer of diabetic or nondiabetic blood were plated in a single well in the same medium (without insulin or glucose). Cells were counted and analyzed as above.

To assess the ability of cells to take up acLDL, $10 \mu \mathrm{g} / \mathrm{mL}$ DiI acLDL (Biomedical Technologies, Stoughton, Massachusetts, USA) was added to the medium, and cells were returned to the incubator for 4 hours. Cells were then washed three times with PBS and examined. The total number of cells was counted using phase microscopy, and the number of DiI acLDL-labeled cells was counted using fluorescence microscopy (due to the DiI tag). The fraction of DiI acLDL-labeled cells was determined from these data. Human coronary artery smooth muscle cells (Cascade Biologicals, Portland, Oregon, USA) were cultured according to the supplier's specifications and used as negative control cells. 
Induction of diabetes. HFh1 $11^{\mathrm{nu}}$ mice (The Jackson Laboratories, Bar Harbor, Maine, USA) at 8 to 12 weeks of age were treated with streptozotocin (STZ; Sigma Chemical Co.) using either of two regimens. To induce moderate diabetes (i.e., some insulin is produced by the mouse) mice were injected intraperitoneally with 40 $\mathrm{mg} / \mathrm{kg} \mathrm{STZ}$ in $0.05 \mathrm{M} \mathrm{Na}$ citrate, $\mathrm{pH} 4.5$, daily for 5 days (26). Three days after the fifth injection, blood glucose levels were measured. If serum glucose was less than $250 \mathrm{mg} / \mathrm{dL}$, mice were injected for an additional 2 days at the same dosage. To induce severe diabetes (i.e., essentially no insulin is produced by the mouse), mice were injected with $160-180 \mathrm{mg} / \mathrm{kg} \mathrm{STZ}$ in a single bolus (27). Three days later, the blood glucose levels were measured. If levels were less than $220 \mathrm{mg} / \mathrm{dL}$, mice were rested 1 week, then injected again with a single bolus of $120 \mathrm{mg} / \mathrm{kg} \mathrm{STZ}$. Mice with a serum glucose level greater than $320 \mathrm{mg} / \mathrm{dL}$ were considered severely diabetic, whereas those with levels of $220-320 \mathrm{mg} / \mathrm{dL}$ were treated as moderately diabetic regardless of treatment method. Glucose levels were retested again 2-3 weeks later to ensure serum glucose levels of greater than $220 \mathrm{mg} / \mathrm{dL}$ in moderately diabetic mice and greater than $320 \mathrm{mg} / \mathrm{dL}$ in severely diabetic mice. Mice with glucose levels less than $220 \mathrm{mg} / \mathrm{dL}$ were excluded from further study. Severely diabetic mice were treated once daily 6 days per week with $2.7 \mathrm{U}$ bovine insulin (Sigma Chemical Co.) in $0.9 \% \mathrm{NaCl}$ beginning 3-6 days after STZ treatment. Mice were diabetic 4-6 weeks before surgery. Serum glucose levels in control mice averaged $121 \mathrm{mg} / \mathrm{dL}$ with a range of $96-144 \mathrm{mg} / \mathrm{dL}$.

Surgical procedures. All procedures were performed on nude (HFh11 ${ }^{\mathrm{nu}}$ ) mice (The Jackson Laboratories) according to University of Iowa Animal Care and Use Committee guidelines. Nude mice were used to minimize possible host-versus-graft immune responses to the transplanted human cells. Surgery was completed essentially as has been described. (28) Under anesthesia (91 $\mu \mathrm{g}$ ketamine plus $10 \mu \mathrm{g}$ xylazine per gram), the mouse was placed ventral side up and a $1-1.5-\mathrm{cm}$ incision made in the skin in the left inguinal area. The femoral artery was then ligated twice with 4-0 silk and transected in two places distal to the ligature. Any other large blood vessels that were visible distal to the ligature were also transected. The wound was closed with 3-0 silk and the mice allowed to recover. Three to 12 hours after surgery the ischemic limb was injected intramuscularly with freshly isolated CM-DiI-labeled CD $34^{+}$cells derived from $40-45 \mathrm{~mL}$ of human blood. The number of CD34+ cells isolated per $40-45 \mathrm{~mL}$ aliquot of blood ranged from $2.5 \times 10^{5}$ to $5.0 \times 10^{5}$ cells. For each $\mathrm{CD} 34^{+}$-injected mice one or more control mice were injected with an equal number of CD34- cells from the same donor. In addition, some mice were injected with an equal volume of buffer (PBS/BSA) or not injected after surgery. Mice were sacrificed 15-18 days later. If mice appeared ill or lost more than $20 \%$ of their body weight at any time during the study, we discontinued their analysis.
Blood-flow analysis. Laser Doppler blood-flow imaging was used to assess the extent of blood-flow restoration in mice after surgery (28). Mice were anesthetized as discussed earlier and placed ventral side up. The hindlimbs were gently immobilized and scanned using a laser Doppler imager (Moor Instruments Inc., Wilmington, Delaware, USA), which measures the flux (blood $\times$ area $^{-1} \times$ time $^{-1}$ ) of blood. The position of the limbs was changed between scans to avoid any positional artifacts. Presurgery scans were performed (3-5 times) either on the day of surgery or 1 day before to determine if flow was similar in both limbs. Postsurgery measurements were done 3-5 times. In some instances the initial scan varied significantly from the subsequent scans and was not included in the data analysis. In such cases, scans were performed until the flux (flow rate per area) measurements were stable for three scans. Mice were scanned immediately after surgery and 1, 2, 4, 6, 8, 10, 12, and 15 days after surgery. For analysis, equal areas $( \pm 5 \%)$ of the control and ischemic limbs from the same anatomical region of the limbs were compared. Mean flux in the selected areas was computed using the Moor imaging software. Data are presented as percentage of mean blood flux in the operated ischemic limb relative to flux in the unoperated control limb. Because presurgery fluxes were not always similar in both limbs, data was normalized to the initial relative fluxes. Only mice whose mean flux in the operated limb immediately after surgery was $\leq 15 \%$ of that of the unoperated control limb were analyzed. Statistical comparisons of blood flux over time among groups were done by a repeated measurements ANOVA and a Bonferroni adjustment using SigmaStat software (SPSS Science, Chicago, Illinois, USA). $P \leq 0.05$ (one-tailed test) was considered statistically significant. To determine the reproducibility of our measurements, eight randomly chosen series of measurements from each of the seven time points were analyzed.

Tissue preparation and immunolabeling. Leg muscles from both control and ischemic limbs and livers were collected immediately after sacrifice, $15-18$ days after surgery. Tissues were fixed in ethanol or ethyl Carnoy's fixative, paraffin embedded, and sectioned at $10 \mu \mathrm{m}$. Tissue-culture cells were rinsed three times in PBS, once in water, and fixed in methanol for 10 minutes. For confocal analysis, liver sections were deparaffinized through three changes of xylenes and coverslipped. For immunostaining, muscle sections were deparaffinized and rehydrated through a series of graded alcohols. Muscle and cultured cells were blocked for 1 hour in 4\% calf serum in PBS, then incubated for 1 hour at room temperature and overnight at $4^{\circ} \mathrm{C}$ in $1 \mu \mathrm{g} / \mathrm{mL}$ rabbit anti-Tie-2 antibody (Santa Cruz Biotechnologies, Santa Cruz, California, USA) or nonimmune rabbit IgG (Sigma Chemical Co.). Tissues or cells were washed three to six times in PBS, incubated 1 to 2 hours in fluorescein-conjugated goat anti-rabbit IgG antibody (Vector Laboratories, Burlingame, California, USA), then washed three to six times in PBS before mounting 
for confocal microscopy. Tissue sections and cells were examined using a Bio-Rad MRC-1024 confocal microscope (Bio-Rad Laboratories, Hercules, California, USA) equipped with a krypton-argon laser or by conventional fluorescence microscopy.

\section{Results}

Enhancement of blood flow by $\mathrm{CD} 34^{+}$cells in ischemic limbs. To investigate the possibility that $\mathrm{CD} 34^{+}$cells can accelerate the restoration of flow to ischemic tissue in vivo, we surgically induced ischemia in the left hindlimb of nude mice. In this well-characterized model, all flow through the femoral artery to the limb is diverted by ligating and then transecting the artery below the ligature. This significantly reduces, but does not abrogate, all flow to the limb in the mouse. For our analysis, we used only mice in which surgical vascular ligation reduced blood flow to $15 \%$ or less of that of presurgery mean-flow levels. The blood flux in the hindlimbs was measured at various times after surgery by laser Doppler blood-flow imaging. Figure 1 shows the images generated by a series of such measurements at various times after surgery. The flow data were analyzed to obtain the mean blood flux in both hindlimbs using Moor imaging software. To assess the rate at which blood flow was restored to the ischemic limbs, blood flux in the ischemic limb was compared with that of the unoperated limb, and the data are expressed as percentage of flow restored relative to the control limb. Multiple measurements were made for each time point, and the mean variability in the measurements was $5.4 \%$ plus or minus $0.5 \%$, with a median value of $4.3 \%$. Differences in presurgery fluxes between the two limbs were accounted for by normalization.

Human CM-DiI-labeled CD34+ cells $(n=8)$, CD34 cells $(n=8)$, vehicle $(n=4)$, or nothing $(n=4)$ were injected into the ischemic limbs of nude mice. As shown in Figure 2a, the restoration of flow in nondia- betic mice is extremely rapid, with $50 \%$ of flow typically being restored by 6 days after surgery. Addition of $\mathrm{CD}^{+} 4^{+}$or CD34- cells did not alter significantly the rate of flow restoration relative to buffer or untreated controls at any time through day 10 (Figure 2a). No significant differences were observed among control groups, so data have been combined.

Because diabetes can inhibit vascularization, we tested the possibility that exogenous $\mathrm{CD} 34^{+}$cells might play a more significant role in restoring blood flow to an ischemic limb in diabetic mice. Ischemic limb surgery was performed on STZ-induced diabetic mice. Mice were treated with CD34 ${ }^{+}$cells $(n=8)$, CD34- cells $(n=7)$, vehicle $(n=4)$, or nothing $(n=6)$, as above. The flow in the ischemic limb relative to the unoperated limb was compared as for nondiabetic mice. Unlike nondiabetic mice, in some cases the presurgery fluxes were significantly different in the two limbs. Also in contrast to nondiabetic mice, diabetic mice treated with $\mathrm{CD} 34^{+}$cells showed a significant improvement in the restoration of flow by 2 days after surgery compared with control groups (Figure 1, Figure 2b). (The data for both moderately and severely diabetic mice are combined since no statistically significant differences or nonsignificant trends were observed between the groups.) The improvement in flow persisted for several days, but by 10 days the difference between $\mathrm{CD} 34^{+}$-treated mice and mice treated with no cells was no longer statistically significant $(P=0.067)$ (Figure $2 b)$. After 10 days, the percentage of flow restored began to converge among all groups (data not shown). In some cases the percent of flow restored in diabetic mice treated with $\mathrm{CD}^{4}{ }^{+}$cells was higher than in nondiabetic mice treated similarly. This does not indicate that flow improves in diabetic mice treated with $\mathrm{CD} 34^{+}$cells relative to nondiabetic controls because presurgery absolute flow is higher in nondiabetic mice than in diabetic mice.
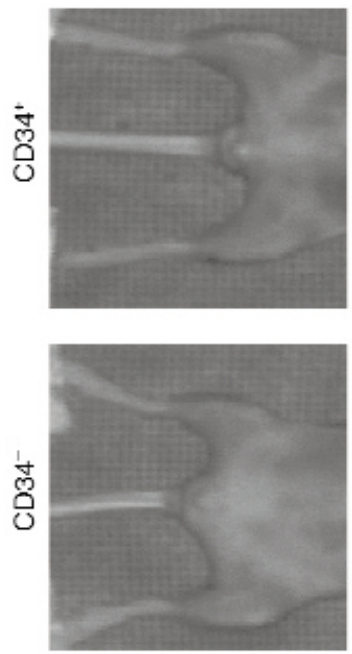

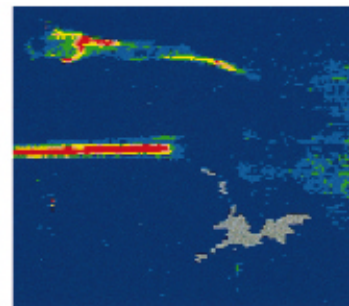

After surgery

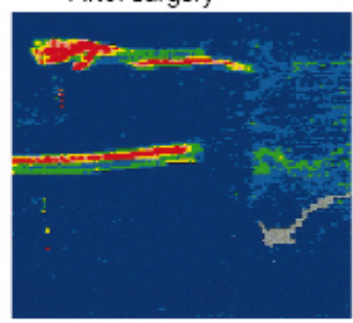

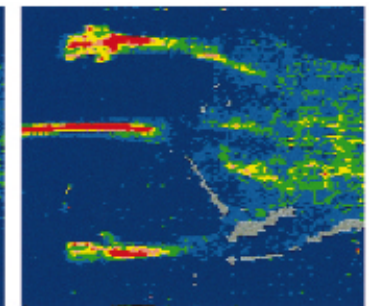

Day 2

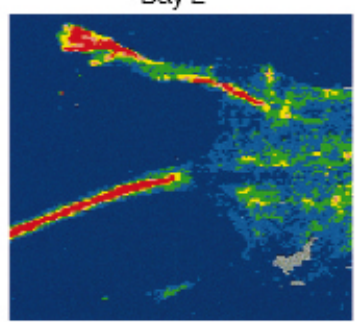

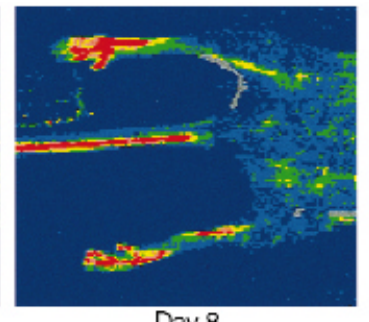

Day 8

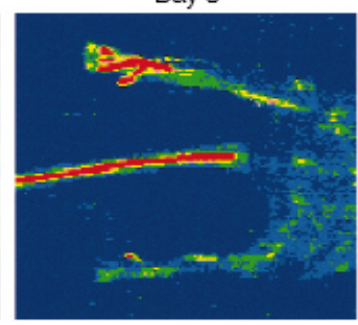

\section{Figure 1}

Laser Doppler blood-flow images. Representation of laser Doppler scans of diabetic mice after left hindlimb iliac artery ligation. Images are of diabetic mice injected with CD34+ cells (top) or CD34- cells (bottom) immediately after, 2 days after, and 8 days after surgery. The mice in the two series had fluxes near the mean for their respective groups at the 3 days shown. Red represents the highest flux and blue/gray the lowest. 


\section{Figure 2}

Restoration of blood flow to surgically induced ischemic limbs. The data are expressed as the percentage of blood flow in the operated limb relative to the contralateral unoperated limb on the same day. Data were normalized to correct for preoperative differences in the two legs. The mean fluxes were determined using laser Doppler imaging for 7-10 mice in each group and were averaged. Error bars represent standard errors. (a) Nondiabetic mice. (b) Diabetic mice (serum glucose $>220 \mathrm{mg} / \mathrm{dL}$ ). $\mathrm{CD} 34^{+}$, injected with $\mathrm{CD} 34^{+}$cells; CD34-, injected with CD34cells; buffer, injected with vehicle or not injected.
We have demonstrated previously that DiI-labeled exogenous human $\mathrm{CD} 34^{+}$cells incorporate into the neovasculature of nondiabetic mice (11). To verify that human $\mathrm{CD}_{3} 4^{+}$cells also incorporate into the diabetic vasculature, limb muscle was harvested from both control and ischemic limbs in the CD34+- and CD34treated mice $15-18$ days after injection of cells. Tissues were then sectioned and examined using confocal microscopy for the presence of red fluorescent CMDiI-labeled cells. CM-DiI-labeled cells were present in the limbs of both $\mathrm{CD} 34^{+}$and $\mathrm{CD} 34^{-}$treated mice, localized predominantly in the muscle of the ischemic limbs and rarely in the nonischemic limbs. To determine if any of the cells present in the limbs were incorporated into the vasculature, sections of limbs were immunolabeled with anti-Tie-2 Abs to delineate newly formed blood vessels. Occasionally CM-DiI/Tie2 -labeled cells were seen in the vasculature in mice injected with CD34- cells. In sections from mice injected with $\mathrm{CD}_{34}{ }^{+}$cells, CM-DiI/Tie-2-labeled vessels were routinely seen, and in some sections numerous vessels that appeared to have incorporated CD $34^{+}$cells were present (Figure 3 and data not shown). CMDiI/Tie-2-labeled cells were almost completely restricted to capillaries. In some mice incorporation into muscular vessels was not observed, and in others it was seen in only one or two sections.

To determine if injected cells remained localized in the muscle, we examined histological sections of livers of $\mathrm{CD}_{3} 4^{+}$and $\mathrm{CD}^{-} 4^{-}$cell-injected mice. CMDiI-labeled cells were found in all liver sections examined from mice treated with $\mathrm{CD} 34^{+}$cells and in some sections from mice treated with CD34- cells. Cells were present in the lumen of blood vessels but did not appear to have incorporated into the local vasculature. (Data not shown.) There appeared to be many more DiI-labeled cells in mice treated with CD34+ cells than in those treated with CD34- cells.
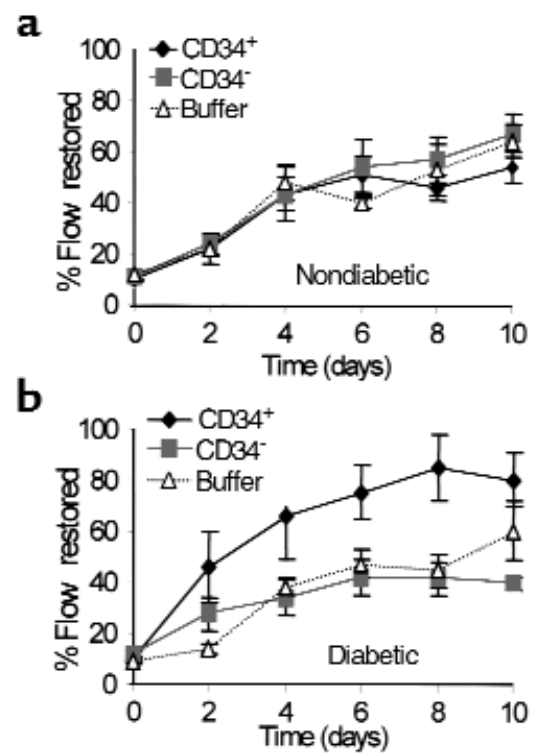

In vitro effects of insulin and glucose on angioblasts. Since our in vivo studies suggested that angioblast function might be altered in diabetic mice, we initiated in vitro studies. In these experiments $\mathrm{CD} 34^{+}$cells were cultured, and the number of spindle-shaped cells produced was counted at various times after plating. Spindle shape was used as the criterion for differentiation into ECs because in our culture system only spindle-shaped cells form tubelike structures, express Tie-2, and take up acLDL (11). In the culture conditions used, more than $95 \%$ of cells are spindle shaped by 6 days in culture.
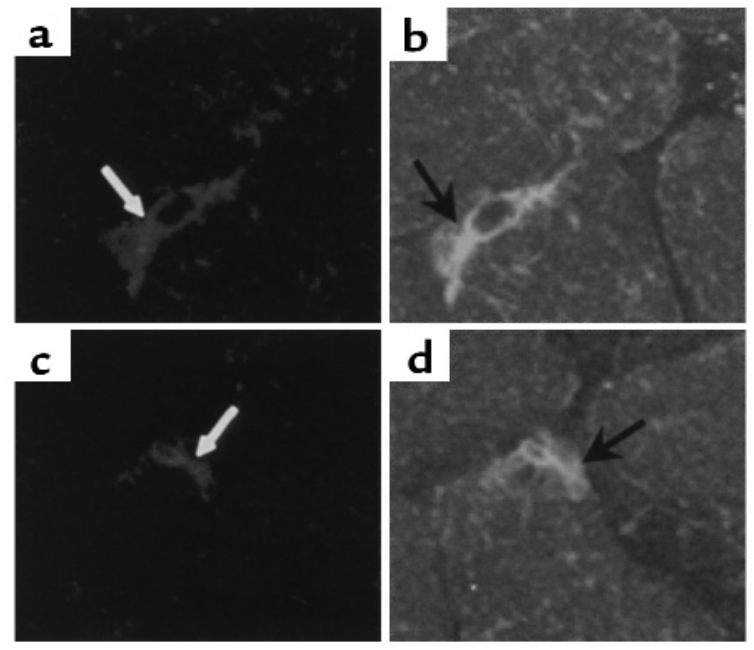

d

Figure 3

$\mathrm{CD} 4^{+}$cells are present in ischemic limb vasculature. Confocal images of $10-\mu \mathrm{m}$ sections of muscle from an ischemic limb of two diabetic mice treated with CM-Dil-labeled CD34+ cells. Sections from muscle collected 18 days after surgery were immunolabeled with FITC-conjugated anti-Tie-2 Ab. (a and $\mathbf{b}$ ) The same section. (c and d) The same section. Confocal images of CM-Dil-labeled cells (white arrows) (a, c) that have formed vessels and are Tie- 2 immunolabeled (black arrows) (b, d). 


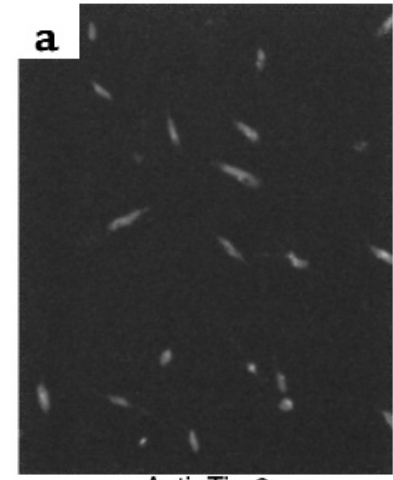

Anti-Tie-2

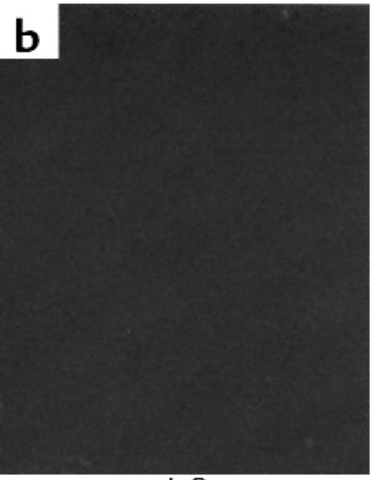

$\lg G$
Figure 4

Anti-Tie-2 immunostaining of CD34 ${ }^{+}$cell cultures. Confocal microscope images of cells immunolabeled 14 days after plating on fibronectin with anti-Tie-2 (a) or rabbit IgG (b), and visualized with FITC.

To assess the effects of glucose on angioblasts, CD34 cells from nondiabetic humans were isolated and cultured in D-glucose, L-glucose, or no glucose. Various concentrations of insulin were added to other cultures to test for possible effects of hyperinsulinemia. Five days after plating, spindle-shaped cells were observed in all cultures. In some experiments we confirmed their identity as ECs by Tie-2 immunolabeling (Figure 4a) and uptake of acLDL (data not shown) $(29,30)$. No labeling of cultured cells was seen in wells incubated with a nonspecific control IgG (Figure 4b). Human coronary artery smooth muscle cells did not take up acLDL or express Tie-2 (data not shown).

The number of spindle-shaped cells per unit area was determined for cultures 4-5 days (as phenotypic differentiation begins), 6-8 days, or 10-14 days after plating. Glucose had no significant effect on the rate of differentiation of angioblasts nor on the number of differentiated cells during this period (Figure 5a). In contrast, $6-18 \mu \mathrm{g} / \mathrm{mL}$ but not $3 \mu \mathrm{g} / \mathrm{mL}$ supplemental insulin altered angioblast behavior (Figure 5b). By 4-5 days after plating, more spindle-shaped cells $(P=$ $0.045)$ were present in insulin-treated cultures than in

\section{Figure 5}

Effects of glucose and insulin on cultured angioblasts. The number of spindle-shaped cells were counted in cultures of freshly isolated CD34 ${ }^{+}$cells plated on fibronectin at various times after plating. Results from four to six experiments at each time point, performed at least in duplicate, are pooled. (a) Cells cultured in medium or medium with $30 \mathrm{mM}$ glucose. Data are presented as percentage of spindle-shaped cells in glucose-treated dishes relative to untreated controls. (b) Cells cultured in medium or medium with $6-12 \mu \mathrm{g} / \mathrm{mL}$ supplemental insulin. Data are presented as percentage of spindleshaped cells in insulin-treated dishes relative to untreated controls. Error bars indicate standard errors for both $\mathbf{a}$ and $\mathbf{b}$. untreated controls. However, in 6-8-day cultures there was no significant difference $(P=0.17)$ in the number of spindle-shaped cells in untreated cultures relative to insulin-treated cultures. In 10-13-day cultures the number of spindle-shaped cells in untreated cultures was significantly larger $(P=0.03)$ than in $6 \mu \mathrm{g} / \mathrm{mL}$ or higher insulin-treated cultures.

In vitro characteristics of angioblasts derived from diabetics. To directly assess possible alterations in angioblast function in diabetics, we analyzed blood from diabetic volunteers. CD $34^{+}$cells were extracted from peripheral blood of diabetics. Blood was obtained from 21 nondiabetic controls and 17 type 2 and 16 type 1 diabetics. As shown in Table 1, there were no significant differences in the number of $\mathrm{CD} 34^{+}$cells selected from type 1 and type 2 diabetics and nondiabetics. The mean enrichment was $72 \pm 9$-fold, and in an earlier study we reported that by using this isolation procedure $15.9 \%$ plus or minus $3.3 \%$ of cells were CD34+ by FACS analysis (11). The selected fractions were then plated at approximately equal cell numbers on fibronectin and examined beginning 3 days after plating and at various times thereafter, up to 14 days. No attached cells were present 3,6 , or 8 days after plating in 4/16 (25\%) nondiabetic, 5/16 (31\%) type I-diabetic, and 4/17 (24\%) type II-diabetic cultures. In all cultures containing attached cells, spindle-shaped cells were detected by 5 days in culture, and no morphological differences were detected among the diabetic and nondiabetic groups.

Cells were examined at various times from 5-14 days after plating, and the number of cells per well were determined. In some experiments cells were immunolabeled with anti-Tie- 2 antibody to verify that the spindle-shaped cells express the EC antigen Tie-2. Greater than $99 \%$ of spindle-shaped cells were immunolabeled. When the number of spindle-shaped cells per well for the different days were compared among groups, no significant differences were observed between diabetics and nondiabetics. However, when diabetics were broken into type 1 and type 2 categories, it became apparent that significantly fewer ECs were produced in cultures derived from type 1 diabetics than from non-

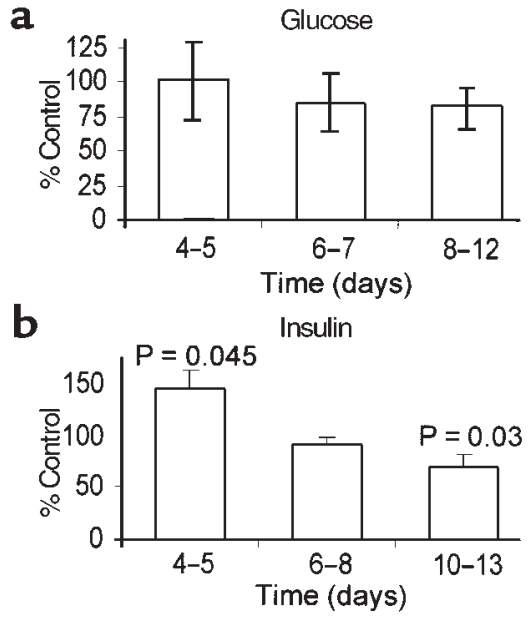


diabetics (Table 1). No significant differences were observed between cultures derived from nondiabetic and type 2 diabetics (Table 1 ).

\section{Discussion}

These results provide evidence that a subset of blood cells can be used to enhance blood flow. Blood flow is restored more rapidly in mice supplemented with exogenous $\mathrm{CD}_{3} 4^{+}$cells compared with non-CD34 ${ }^{+}$ cell-supplemented mice, although flows eventually reach similar levels in both groups. In this model, where flow is normally restored relatively rapidly, the benefit of an acceleration in vascularization may not be obvious. However, in larger animals and humans, where restoration of flow is much slower, this acceleration may be of profound importance and could mean the difference between saving and losing a limb. We are investigating the use of exogenous angioblasts to restore flow in larger animals. Furthermore, although our model focused specifically on the ischemic limb, it is possible that the findings may be significant with respect to rapidly restoring blood flow to infarcted regions of the heart or the brain after a stroke.

Why exogenous $\mathrm{CD} 34^{+}$cells helped accelerate flow restoration in diabetic, but not nondiabetic, mice is unclear. It is possible that exogenous cells are of little value to animals that already have a fully functioning complement of $\mathrm{CD} 34^{+}$cells and can help only in animals with compromised $\mathrm{CD} 34^{+}$cell function or with a smaller complement of angioblasts. Accordingly, it may be that in the absence of induced hindlimb ischemia, exogenous angioblasts can restore baseline flow in the hindlimbs of diabetic mice to levels seen in nondiabetic mice. We are currently testing this possibility. Because flow is restored so rapidly in our mouse model, it is possible that our measurements were not sensitive enough to pick up a CD $34^{+}$cell enhancement in nondiabetic mice. This possibility is supported by recent data indicating that cultured $\mathrm{CD} 34^{+}$cells can accelerate revascularization in an ischemic limb in nondiabetic mice (31). In this model flow is restored to $50 \%$ of presurgery levels in 14 days, whereas in our mice flow is typically restored to $60 \%$ of presurgery levels in 10 days and $90-100 \%$ by 14 days.

It is surprising that $\mathrm{CD} 34^{+}$cell-induced acceleration in the restoration of flow occurs so rapidly in diabetic mice. One possibility is that the exogenous cells cause vasodilation. While possible, it is puzzling that only CD $34^{+}$cells and not CD34- cells exert this effect and that it is observed only in diabetic mice. Our histological data clearly indicate that $\mathrm{CD} 34^{+}$cells directly incorporate into the vasculature, but their contribution does not appear to be great enough to account for the rapid and large acceleration in blood flow. We suggest that the acceleration of flow restoration may be due to a combination of effects. Incorporation of exogenous $\mathrm{CD} 34^{+}$cells or endogenous angioblasts, in the case of nondiabetics, into a vessel may accelerate vascular growth by both increasing the number of ECs, but more importantly, by releasing factors that induce the proliferation of existing ECs and recruiting smooth muscle cells. A third component could be vasodilation.

The question of whether angioblast function is impaired in diabetics remains open, but our data suggest that it is. More ECs are produced in cultures of $\mathrm{CD} 34^{+}$cells derived from nondiabetics than from type 1 diabetics, although type 2 diabetes does not affect in vitro EC production. Since both type 1 and type 2 diabetics are hyperglycemic, it is unlikely that hyperglycemia is a significant cause of the observed difference. This is consistent with our in vitro findings in which glucose had no apparent effect on EC production. It did not alter the time at which differentiated ECs were first observed, their rate of their production over time, or their morphology. Although in our in vitro system glucose had no obvious direct effect on angioblasts, we do not suggest that it has no role in vivo. In vivo, hyperglycemia alters many molecules that impact on leukocyte- and endothelial-cell function and, thus, may have effects on angioblast function that are not readily observable in this culture system.

One major difference between type 1 and type 2 diabetics is that the former are hypoinsulinemic, and the latter are typically hyperinsulinemic. Could hypoinsulinemia be responsible for the different behaviors of type 1 and type 2 diabetic cells in culture? Our in vitro data support this, in that insulin accelerates differentiation of nondiabetic $\mathrm{CD} 34^{+}$cells into ECs. However, if hypoinsulinemia inhibits angioblast differentiation, why do $\mathrm{CD} 34^{+}$cells accelerate the restoration of blood flow in hypoglycemic mice. Would not their differentiation be inhibited? Many more experiments are needed to address this question, but perhaps exposure to insulin primes cells for differentiation. Thus, for example, the long-term exposure of nondiabetic and type 2 diabetic cells to insulin may have primed them to differentiate even in a hypoinsulinemic environment. In culture, prolonged exposure to insulin might be mimicked by exposing cells to high levels of insulin for short periods. Further, if insulin is required for the production of angioblasts, the number of angioblasts (albeit not the
Table 1

Effects of diabetes on in vitro production of blood-derived EC

\begin{tabular}{|c|c|c|c|}
\hline Number of Subjects & $\begin{array}{c}\text { Nondiabetic } \\
\text { Control } \\
21\end{array}$ & $\begin{array}{c}\text { Type I } \\
\text { Diabetic } \\
17\end{array}$ & $\begin{array}{c}\text { Type II } \\
\text { Diabetic } \\
16\end{array}$ \\
\hline $\begin{array}{l}\text { Number of CD34+ } \\
\text { cells isolated (mean) }\end{array}$ & $2.7 \times 10^{5} \pm 5.4 \times 10^{4}$ & $2.1 \times 10^{5} \pm 4.5 \times 10^{4}$ & $2.7 \times 10^{5} \pm 5.7 \times 10^{4}$ \\
\hline$P$ (Relative to nondiabetic) & & $P>0.05$ & $P>0.05$ \\
\hline Cells per well (mean) & $3410 \pm 1034$ & $990 \pm 418$ & $4158 \pm 1452$ \\
\hline$P$ (Relative to nondiabetic) & & $P=0.046$ & $P>0.05$ \\
\hline
\end{tabular}


number of CD $34^{+}$cells) may be decreased in type 1 diabetics. Exogenous cells could be providing a supply of cells that are normally lacking in hypoinsulinemic mice.

It is interesting that although hyperinsulinemia initially increased the number of ECs present in CD34 ${ }^{+}$ cultures, as cells remained in culture long term, the number of ECs actually decreased in hyperinsulinemic cultures. This suggests that whereas insulin may have a stimulatory effect on angioblast production and/or differentiation, it may subsequently decrease either the viability or rate of growth of the differentiated ECs. It also appears that there is a threshold for this response since a low dose of insulin did not noticeably alter angioblast behavior in the cultures.

The data reported here suggest that angioblast function may be impaired or their numbers reduced in type I diabetics. These findings also provide evidence that angioblasts can be used to enhance the restoration of blood flow to ischemic tissue, suggesting a potential for exogenous angioblasts in therapeutic angiogenesis. However, as demonstrated by the presence of CMDiI-labeled cells in the liver, an investigation of the distribution of injected cells and an examination of possible functional consequences of their incorporation into nonischemic tissues will be an important first step in determining whether angioblasts may someday be useful therapeutic agents.

\section{Acknowledgments}

The authors wish to thank Robert Tomanek and Don Sheriff for helpful discussions, and Bridgett Zimmermann for help with statistical analysis. We also thank our blood donors and Robert Spanheimer, William Sivitz, and the staff of the University of Iowa Clinic C for help in collecting blood. Confocal microscopy was performed at the University of Iowa Central Microscopy Research Facility. The work was supported by the American Heart Association, Texas Affiliate Grant-In-Aid 97G-44, and a joint $\mathrm{NIH}$ and Juvenile Diabetes Foundation International Grant RO1 DK-55965.

1. Hueper, W.C., and Russell, M.A. 1932. "Capillary-like formations" in tissue cultures of leukocytes. Archiv für Experimentelle Zellforschung Besoners Gewebezüchtung. 12:407-424.

2. Parker, R.C. 1933. The development of organized vessels in cultures of blood cells. Science. 77:544-546.

3. White, J.F., and Parshley, M.S. 1950. Growth in vitro of blood vessels from bone marrow of adult chickens. Am. J. Anat. 89:321-345.

4. Hladovec, J., and Rossmann, P. 1973. Circulating endothelial cells isolated together with platelets and the experimental modification of their counts in rats. Thromb. Res. 3:665-674.

5. Solovey, A., et al. 1997. Circulating activated endothelial cells in sickle cell anemia. N. Engl. J. Med. 337:1584-1590.

6. Stump, M.M., Jordan, J.L., Jr., DeBakey, M.E., and Halpert, B. 1963. Endothelium grown from circulating blood on isolated intravascular
Dacron hub. Am. J. Pathol. 43:361-367.

7. Mackenzie, J.R., Hackett, M., Topuzlu, C., and Tibbs, D.J. 1968. Origin of arterial prosthesis lining from circulating blood cells. Arch. Surg. 97:879-885

8. Scott, S.M., Barth, M.G., Gaddy, L.R., and Ahl, E.T. 1994. The role of circulating cells in the healing of vascular prostheses. J. Vasc. Surg. 19:585-593

9. Shi, Q., et al. 1994. Proof of fallout endothelialization of impervious Dacron grafts in the aorta and inferior vena cava of the dog. J. Vasc. Surg. 20:546-556.

10. Wu, M.H., et al. 1995. Definitive proof of endothelialization of a Dacron prosthesis in a human being. J. Vasc. Surg. 21:862-867.

11. Asahara, T., et al. 1997. Isolation of putative progenitor endothelial cells for angiogenesis. Science. 275:964-967.

12. Takahashi, T., et al. 1999. Ischemia- and cytokine-induced mobilization of bone marrow-derived endothelial progenitor cells for neovascularization. Nat. Med. 5:434-438.

13. Siena, S., et al. 1989. Circulation of CD34 $4^{+}$hematopoietic stem cells in the peripheral blood of high-dose cyclophosphamide-treated patients: enhancement by intravenous recombinant human granulocytemacrophage colony-stimulating factor. Blood. 74:1905-1914.

14.Ziegler, B.L., et al. 1999. KDR receptor: a key marker defining hematopoietic stem cells. Science. 285:1553-1558.

15. Spangrude, G.J., Heimfeld, S., and Weissman, I.L. 1988. Purification and characterization of mouse hematopoietic stem cells. Science. 241:58-62.

16. Uchida, N., and Weissman, I.L. 1992. Searching for hematopoietic stem cells: evidence that Thy-1.1lo Lin-Sca-1+ cells are the only stem cells in C57BL/Ka-Thy-1.1 bone marrow. J. Exp. Med. 175:175-184.

17. Choi, K., Kennedy, M., Kazarov, A., Papadimitriou, J.C., and Keller, G. 1998. A common precursor for hematopoietic and endothelial cells. Development. 125:725-732

18. Eichmann, A., et al. 1997. Ligand-dependent development of the endothelial and hemopoietic lineages from embryonic mesodermal cells expressing vascular endothelial growth factor receptor 2. Proc. Natl. Acad. Sci. USA. 94:5141-5146.

19. Asahara, T., et al. 1999. Bone marrow origin of endothelial cells responsible for postnatal vasculogenesis in physiological and pathological neovascularization. Circ. Res. 85:221-228

20.1994. Prevention of diabetes mellitus. World Health Organization. Geneva, Switzerland. Technical Report Series, No. 844.100 pp. ISBN 9241208449

21. Meigs, J.B., et al. 1997. Metabolic control and prevalent cardiovascular disease in non-insulin-dependent diabetes mellitus (NIDDM): The NIDDM Patient Outcome Research Team. Am. J. Med. 102:38-47.

22. Feener, E.P., and King, G.L. 1997. Vascular dysfunction in diabetes mellitus. Lancet. 350(Suppl. 1):SI9-SI13.

23. Rivard, A., et al. 1999. Rescue of diabetes-related impairment of angiogenesis by intramuscular gene therapy with adeno-VEGF. Am. J. Pathol. 154:355-363.

24. Demirer, T., and Bensinger, W.I. 1995. Optimization of peripheral blood stem cell collection. Curr. Opin. Hematol. 2:219-226.

25. Wagemaker, G., Neelis, K.J., and Wognum, A.W. 1995. Surface markers and growth factor receptors of immature hemopoietic stem cell subsets. Stem Cells. 13(Suppl. 1):165-171.

26. Kunjathoor, V.V., Wilson, D.L., and LeBoeuf, R.C. 1996. Increased atherosclerosis in streptozotocin-induced diabetic mice. J. Clin. Invest. 97:1767-1773.

27. Vidal-Puig, A., et al. 1996. Regulation of PPAR gamma gene expression by nutrition and obesity in rodents. J. Clin. Invest. 97:2553-2561.

28. Couffinhal, T., et al. 1998. Mouse model of angiogenesis. Am. J. Pathol. 152:1667-1679.

29. Schnurch, H., and Risau, W. 1993. Expression of Tie-2, a member of a novel family of receptor tyrosine kinases, in the endothelial cell lineage. Development. 119:957-968.

30. Stein, O., and Stein, Y. 1980. Bovine aortic endothelial cells display macrophage-like properties towards lipoacetylated ${ }^{125}$ I-labeled low density lipoprotein. Biochim. Biophys. Acta. 620:631-635.

31. Kalka, C., et al. 2000. Transplantation of ex vivo expanded endothelial progenitor cells for therapeutic neovascularization. Proc. Natl. Acad. Sci. USA. 97:3422-3427. 